\title{
Expiratory and Expiratory Plus Inspiratory Muscle Training Improves Respiratory Muscle Strength in Subjects With COPD: Systematic Review
}

\author{
Leonardo F Neves PT, Manoela H Reis PT, Rodrigo DM Plentz PT ScD, \\ Darlan L Matte PT ScD, Christian C Coronel PT MSc, and Graciele Sbruzzi PT ScD
}

BACKGROUND: Inspiratory muscle training (IMT) produces beneficial effects in COPD subjects, but the effects of expiratory muscle training (EMT) and EMT plus IMT in ventilatory training are still unclear. The aim of this study was to systematically review the effects of EMT and EMT plus IMT compared to control groups of COPD subjects. METHODS: This study is a systematic review and meta-analysis. The search strategy included MEDLINE, Embase, LILACS, PEDro, and Cochrane CENTRAL and also manual search of references in published studies on the subject. Randomized trials comparing EMT and EMT plus IMT versus control groups of subjects with COPD were included. The outcomes analyzed were respiratory muscle strength and functional capacity. Two reviewers independently extracted the data. RESULTS: The search retrieved 609 articles. Five studies were included. We observed that EMT provided higher gain in maximum expiratory pressure $\left(\mathrm{P}_{\mathrm{E}_{\max }} 21.49 \mathrm{~cm} \mathrm{H_{2 }} \mathrm{O}, 95 \%\right.$ CI 13.39-29.59) and maximum inspiratory pressure $\left(\mathrm{P}_{\mathrm{I}_{\max }} 7.68 \mathrm{~cm} \mathrm{H}_{2} \mathrm{O}, 95 \%\right.$ CI 0.90-14.45) compared to control groups. There was no significant difference in the 6-min walk test distance $(29.01 \mathrm{~m}, 95 \% \mathrm{CI}-39.62$ to 97.65$)$ and dyspnea $(0.15$, 95\% CI -0.77 to 1.08). In relation to EMT plus IMT, we observed that $\mathrm{P}_{\mathrm{E}_{\max }}\left(31.98 \mathrm{~cm} \mathrm{H}_{2} \mathrm{O}\right.$, 95\% CI 26.93-37.03) and $P_{I_{\max }}\left(27.98 \mathrm{~cm} \mathrm{H}_{2} \mathrm{O}, 95 \%\right.$ CI 20.10-35.85) presented higher values compared to control groups. CONCLUSIONS: EMT and EMT plus IMT improve respiratory muscle strength and can be used as part of the treatment during pulmonary rehabilitation of subjects with severe to very severe COPD. Key words: COPD; obstructive pulmonary disease; pulmonary diseases; chronic obstructive; expiratory muscle training; breathing exercise; respiratory muscle training. [Respir Care 2014;59(9):1381-1388. (C) 2014 Daedalus Enterprises]

\section{Introduction}

COPD is one of the major causes of death worldwide. In 1990 , it was the sixth main cause of death; in 2000, the fourth; and in 2020, it will be the third major cause of

Mr Neves, Ms Reis, Dr Plentz, Mr Coronel, and Dr Sbruzzi are affiliated with the Instituto de Cardiologia do Rio Grande do Sul, Fundação Universitária de Cardiologia, Porto Alegre, Rio Grande do Sul, Brazil. Dr Plentz is also affiliated with the Universidade Federal de Ciências da Saúde de Porto Alegre, Porto Alegre, Rio Grande do Sul, Brazil, and Dr Sbruzzi is also affiliated with Universidade Federal do Rio Grande do Sul, Porto Alegre, Rio Grande do Sul, Brazil. Dr Matte is affiliated with the Universidade Estadual de Santa Catarina, Florianópolis, Santa Catarina, Brazil.

The authors have disclosed no conflicts of interest. death in the world. ${ }^{1}$ Moreover, it is considered one of the main causes of death in Europe, ${ }^{1}$ in the United States, ${ }^{2}$ and in Brazil. ${ }^{3}$ COPD can cause systemic alterations such as systemic inflammation, skeletal muscle dysfunction, peripheral muscle weakness, and inspiratory and expiratory muscle weakness caused by changes in the composition of muscle fibers and muscle atrophy. ${ }^{4-6}$ Thus, the treatment of this disease should be multidisciplinary, and respiratory

Correspondence: Graciele Sbruzzi PT ScD, Rua Felizardo, 750, Bairro, Jardim Botânico, Porto Alegre, Rio Grande do Sul 90690-200, Brazil. E-mail: graciele.sbruzzi@ufrgs.br.

DOI: $10.4187 /$ respcare. 02793 


\section{Respiratory Muscle Training in Subjects With COPD}

physiotherapy may act by improving the functional capacity of these subjects. ${ }^{6,7}$

Respiratory muscle training is a part of rehabilitation for COPD subjects, as it promotes benefits such as improved pulmonary function and respiratory muscle strength, ${ }^{4}$ reduction of dyspnea severity, ${ }^{8}$ improved exercise tolerance, ${ }^{9}$ and enhanced functionality and quality of life. ${ }^{8}$ Studies that prove the efficacy of inspiratory muscle training (IMT) in subjects with COPD are well documented in the literature, demonstrating that this training leads to a reduction of dyspnea and improvement in pulmonary function, respiratory muscle strength, and functional capacity. ${ }^{10-12}$ However, the results of expiratory muscle training (EMT) in these subjects are not conclusive.

It has been demonstrated in the literature that specific EMT is efficient in improving strength and endurance of expiratory muscles compared to a control group (low load of $\left.7 \mathrm{~cm} \mathrm{H}_{2} \mathrm{O}\right)^{4,13}$; however, some authors found no significant effects of EMT on some outcomes such as decreased sensation of dyspnea. ${ }^{4}$ Thus, some authors do not recommend EMT when treating subjects with COPD due to the lack of scientific evidence and methodologically well-designed evidence. ${ }^{14,15}$ Therefore, there still appears to be a disagreement in the literature about the benefits of EMT in increasing strength and endurance in subjects with COPD. Hence, the purpose of this study was to determine the influence of EMT and EMT plus IMT compared to control groups in subjects with COPD, evaluating the outcomes of maximum expiratory and inspiratory muscle pressure, 6-min walk test (6MWT) distance, and dyspnea, through a systematic review and meta-analysis.

\section{Methods}

This study was approved by the Ethics Committee in Research of the Instituto de Cardiologia do Rio Grande do Sul, Fundação Universitária de Cardiologia, Porto Alegre, Rio Grande do Sul, Brazil (number 4673/11), and follows the recommendations proposed by the Cochrane Collaboration $^{16}$ and the PRISMA Statement. ${ }^{17}$

\section{Eligibility Criteria}

We included randomized control trials (RCTs) that compared EMT versus a control group or EMT plus IMT versus a control group in subjects with COPD, which evaluated any of the following outcomes: maximum expiratory pressure $\left(\mathrm{P}_{\mathrm{E}_{\max }}, \mathrm{cm} \mathrm{H}_{2} \mathrm{O}\right)$, maximum inspiratory pressure $\left(\mathrm{P}_{\mathrm{I}_{\max }}, \mathrm{cm} \mathrm{H} \mathrm{H}_{2} \mathrm{O}\right)$, distance (or exercise tolerance) in 6MWT (meters), and dyspnea (Borg scale). EMT was considered as expiration against a resistance device, which could be a threshold or any other equipment that aimed to increase air-flow resistance during expiration. EMT is usually performed in a threshold device with a percentage of the $\mathrm{P}_{\mathrm{E}_{\max }}$

\section{QUICK LOOK}

\section{Current knowledge}

Inspiratory muscle training (IMT) as part of a pulmonary rehabilitation program for patients with COPD is designed to improve pulmonary function, increase respiratory muscle strength, reduce dyspnea, increase exercise tolerance, and improve quality of life.

\section{What this paper contributes to our knowledge}

The results of this systematic review and meta-analysis demonstrate that expiratory muscle training and IMT increase respiratory muscle strength but fail to improve functional capacity and or reduce dyspnea. Studies with larger sample sizes and improved methodological rigor are needed to further define this relationship.

for the purpose of increasing expiratory muscle strength. Exclusion criteria were summarized as follows: hospitalization during the training period and studies using pursed-lip breathing or CPAP for EMT. If a trial had multiple publications (or substudies), the study was included only once.

\section{Search Strategy}

We searched the following electronic databases independently, in duplicate, from inception to February 2013: MEDLINE (accessed by PubMed), Physiotherapy Evidence Database (PEDro), Cochrane Central Register of Controlled Trials (CENTRAL), Embase, and LILACS. In addition, we performed a manual search of references in published studies on the subject. The search was performed on February 18, 2013, and included the following terms: "Breathing Exercises," "Chronic Obstructive Pulmonary Disease," "Exercise, Breathing," "Respiratory Muscle Training," "Expiratory Muscles Training," "Inspiratory Muscles Training," "pulmonary disease, chronic obstructive," "COPD," "Obstructive Pulmonary Disease" (associated with a list of sensitive terms to search for RCTs, prepared by Robinson and Dickersin ${ }^{18}$ ). The search strategy used to in PubMed is provided in Table 1. There was no language restriction in the search.

\section{Study Selection and Data Extraction}

The titles and abstracts of all articles identified by the search were evaluated by 2 independent reviewers. All abstracts that did not provide sufficient information on the inclusion and exclusion criteria were selected to evaluate the full text. In this second phase, the same reviewers independently assessed the full articles and made their 
Table 1. Search Strategy Used in PubMed

\begin{tabular}{|c|c|}
\hline$\# 1$ & $\begin{array}{l}\text { "pulmonary disease, chronic obstructive"[MeSH] OR "pulmonary disease, chronic obstructive" OR "COPD" OR "chronic obstructive } \\
\text { pulmonary disease" OR "COAD" OR "chronic obstructive airway disease" OR "chronic obstructive lung disease" OR "airflow } \\
\text { obstruction, chronic" OR "airflow obstructions, chronic" OR "chronic airflow obstructions" OR "chronic airflow obstruction" }\end{array}$ \\
\hline$\# 2$ & $\begin{array}{l}\text { "breathing exercises" }[\mathrm{MeSH}] \text { OR "breathing exercises" OR "exercise, breathing" OR "respiratory muscle training" OR "muscle training, } \\
\text { respiratory" OR "training, respiratory muscle" OR "expiratory muscle training" }\end{array}$ \\
\hline \#3 & $\begin{array}{l}\text { (randomized controlled trial[pt] OR controlled clinical trial[pt] OR randomized controlled trials[mh] OR random allocation[mh] } \\
\text { OR double-blind method[mh] OR single-blind method[mh] OR clinical trial[pt] OR clinical trials[mh] OR ("clinical trial"'[tw]) } \\
\text { OR ( (singl*[tw] OR doubl*[tw] OR trebl*[tw] OR tripl*[tw]) AND (mask*[tw] OR blind*[tw])) OR ("latin square"[tw]) OR } \\
\text { placebos[mh] OR placebo*[tw] OR random*[tw] OR research design[mh:noexp] OR follow-up studies[mh] OR prospective } \\
\text { studies[mh] OR crossover studies[mh] OR control*[tw] OR prospectiv*[tw] OR volunteer*[tw]) NOT (animal[mh] NOT human[mh]) }\end{array}$ \\
\hline 4 & \#1 AND \#2 AND \#3 \\
\hline
\end{tabular}

$\overline{\mathrm{MeSH}}=$ Medical Subject Heading

$\mathrm{pt}=$ publication type

$\mathrm{mh}=$ MeSH Heading

$\mathrm{tw}=$ term entered by user

selections according to the eligibility criteria pre-specified. Disagreements between reviewers were resolved by consensus. Using standardized forms, the same 2 reviewers independently conducted data extraction with regard to the methodological characteristics of the studies, interventions, and outcomes; disagreements were also solved by consensus. When the study did not have all necessary data for meta-analysis, the corresponding author was contacted to request the missing data.

\section{Assessment of Risk of Bias}

The methodological quality assessment was performed by 2 investigators independently using a Cochrane assessment and took into consideration the following characteristics of included studies: randomized sequence generation, allocation concealment, blinding of outcome assessors, intention to treat analysis, and description of losses and exclusions. Studies without a clear description of these items were considered as unclear or not reporting the latter.

\section{Data Analysis}

The meta-analysis was performed using weighted mean difference, a random effects model, and $95 \% \mathrm{CI}$, and the measures of effect were obtained by post-intervention values. The studies were analyzed separately from the type of intervention: EMT versus the control group or EMT plus IMT versus the control group. All analyses were conducted using Review Manager 5.1 (Cochrane Collaboration). ${ }^{16}$ Statistical heterogeneity of the treatment effects among studies was assessed using Cochran's Q test and the inconsistency $\mathrm{I}^{2}$ test, in which values above 25 and $50 \%$ were considered to indicate moderate and high heterogeneity, respectively. ${ }^{19}$

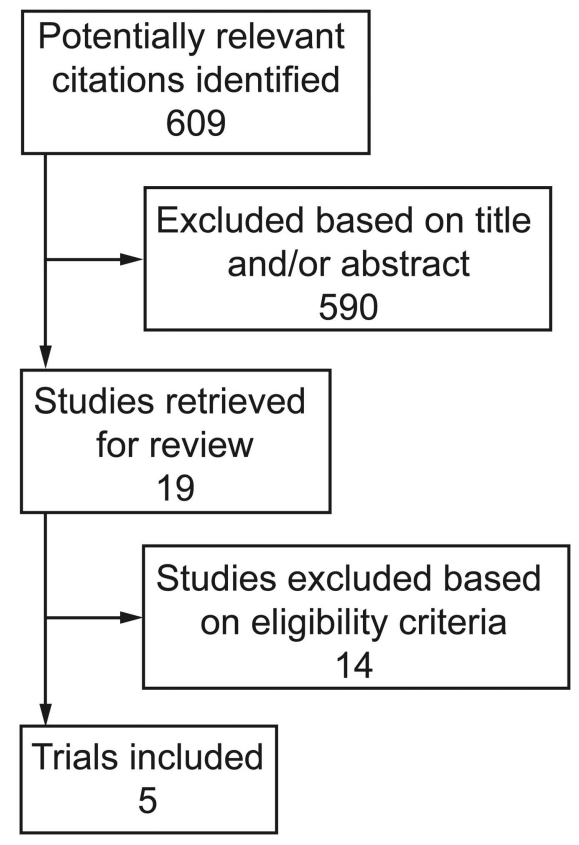

Fig. 1. Flow diagram of the studies included in this review.

\section{Results}

\section{Description of Studies}

The initial search identified 609 abstracts, 19 of which were considered potentially relevant. Only 5 studies $^{4,8,13,20,21}$ met the eligibility criteria and were included in this systematic review. The studies selected and the flow chart are shown in Figure 1.

The 5 studies included had a total of 111 subjects. One of the studies was used twice ${ }^{13}$ because of the different comparisons, so the control group was counted only once 
for the total subjects studied. The characteristics of the studies are summarized in Table 2. Four trials ${ }^{4,8,13,20} \mathrm{com}-$ pared EMT versus a control group (total $n=71$, EMT group $n=37$ ), whereas 2 trials ${ }^{13,21}$ compared EMT and IMT versus a control group (total $n=48$, EMT and IMT group $n=24)$. None of the 5 studies reported detrimental effects of EMT.

The training load ranged from 10 to $60 \%$ of $\mathrm{P}_{\mathrm{E}_{\max }}$ between studies. The duration of each session in the studies ranged between 15 and $30 \mathrm{~min}$, with total time varying from 5 to 40 weeks of training. All studies included individuals with GOLD (Global Initiative for Chronic Obstructive Lung Disease) stage III and/or IV of severity.

\section{Risk of Bias}

Of the included studies in the systematic review, all studies presented an adequate sequence generation, 20\% reported allocation concealment, $40 \%$ had a blinded assessment of outcomes, $80 \%$ described losses to follow-up and exclusions, and $60 \%$ used the intention-to-treat principles for statistical analyses (Table 3).

\section{Effects of Interventions}

\section{Analysis 1: Expiratory Muscle Training Versus Con- trol Group}

Respiratory Muscle Strength: $\mathbf{P}_{\mathbf{E}_{\max }}$ and $\mathbf{P}_{\mathbf{I}_{\max }}$. Four trials $s^{4,8,13,20}(n=71)$ comparing EMT to a control group evaluated $\mathrm{P}_{\mathrm{E}_{\max }}$, and 3 articles ${ }^{4,13,20}(n=55)$ evaluated $\mathrm{P}_{\mathrm{I}}$. We observed that EMT provides a higher gain in $\mathrm{P}_{\mathrm{E}_{\max }}\left(21.49 \mathrm{~cm} \mathrm{H}_{2} \mathrm{O}, 95 \% \mathrm{CI} 13.39-29.59, \mathrm{I}^{2}=0 \%\right)$ and $\mathrm{P}_{\mathrm{I}_{\max }}\left(7.68 \mathrm{~cm} \mathrm{H}_{2} \mathrm{O}, 95 \%\right.$ CI $0.90-14.45, \mathrm{I}^{2}=0 \%$ ) (Fig. 2) compared to control groups.

Functional Capacity. Three $\operatorname{articles}^{4,8,13}(n=55)$ evaluated distance walked in 6MWT, and 2 studies $^{8,20}$ $(n=32)$ assessed dyspnea. There was no significant difference in 6MWT $(29.01 \mathrm{~m}, 95 \% \mathrm{CI}-39.62$ to 97.65 , $\mathrm{I}^{2}=0 \%$ ) (Fig. 3). Figure 4 illustrates that there is no difference between EMT and a control group for dyspnea $\left(0.15,95 \%\right.$ CI -0.77 to $\left.1.08, \mathrm{I}^{2}=0 \%\right)$.

Analysis 2: Expiratory Muscle Training Combined With Inspiratory Muscle Training Versus Control Group

Respiratory Muscle Strength: $\mathbf{P}_{\mathbf{E}_{\max }}$ and $\mathbf{P}_{\mathbf{I}_{\max }}$. The 2 trials $^{13,21}(n=48)$ comparing EMT plus IMT to a control group evaluated $\mathrm{P}_{\mathrm{E}_{\max }}$ and $\mathrm{P}_{\mathrm{I}_{\max }} \cdot \mathrm{P}_{\mathrm{E}_{\max }}$ had higher values in the combined EMT and IMT group $\left(31.98 \mathrm{~cm} \mathrm{H}_{2} \mathrm{O}, 95 \% \mathrm{CI}\right.$ 26.93-37.03) than in the control group (Fig. 5). EMT combined with IMT also showed higher results for $\mathrm{P}_{\mathrm{I}_{\max }}$
(27.98 $\mathrm{cm} \mathrm{H}_{2} \mathrm{O}, 95 \%$ CI 20.10-35.85) compared to the control group (Fig. 5). There were insufficient data to perform the meta-analysis with these articles evaluating functional capacity.

\section{Discussion}

\section{Summary of Evidence}

In this systematic review and meta-analysis of RCTs, we wanted to evaluate the influence of EMT and EMT plus IMT compared to control groups in subjects with COPD, evaluating respiratory muscle training and functional capacity. We observed that EMT and EMT combined with IMT provide higher gains in $\mathrm{P}_{\mathrm{E}_{\max }}$ and $\mathrm{P}_{\mathrm{I}_{\max }}$ compared to control groups, but not in functional capacity and dyspnea.

The data analyzed demonstrated that EMT provides benefits in $\mathrm{P}_{\mathrm{I}_{\max }}{ }^{4,13,20}$ and $\mathrm{P}_{\mathrm{E}_{\max }}{ }^{4,8,13,20}$ Studies have shown that respiratory muscle weakness is associated with increased mortality in subjects with COPD. ${ }^{22}$ In addition, expiratory muscle weakness is a risk factor for re-admission to hospital due to exacerbations, ${ }^{23}$ and a recent study showed that the degree of air-flow obstruction and hyperinflation at hospitalization is related to expiratory muscle strength. ${ }^{24} \mathrm{Also}$, it is known that severe acute exacerbations have an independent negative impact on the prognosis for COPD patients..$^{25}$ These data demonstrate the importance of treating muscle strength in subjects with COPD. In a practice guideline for physiotherapists treating subjects with COPD, ${ }^{14}$ cough effectiveness and forced expiration are important clinical conditions to decrease retention of mucus and avoid respiratory infections and are recommended as a way to treat COPD subjects. Therefore, the favorable outcomes shown in this paper can contribute to these objectives.

Moreover, it is known that expiratory muscles are activated during expiration in subjects with COPD, most often at the end of expiration. ${ }^{26}$ Weiner et al ${ }^{13}$ demonstrated that when IMT is performed alone, there is no improvement in $\mathrm{P}_{\mathrm{E}_{\max }}$. Therefore, it is important that COPD subjects perform EMT to increase $P_{E_{\max }}$.

Hyperinflation is common in subjects with COPD and can be caused by daily activities or exercise, and this increases the sensation of dyspnea and, in advanced COPD subjects, can reflect $\mathrm{CO}_{2}$ retention during exercise. ${ }^{27-29}$ Although no significant difference was found, hyperinflation was reduced in the group that performed EMT in one of the studies, and it is possible that EMT decreases hyperinflation, improving abdominal muscle tone and decreasing the elevation of the diaphragm. ${ }^{8}$

In relation to distance walked in 6MWT and dyspnea, there was no significant improvement for EMT. The distance walked is associated with clinical outcomes such as hospitalization and mortality. ${ }^{30,31}$ Changes in 6MWT distance are used to evaluate the efficacy of therapeutic 


\section{Respiratory Muscle Training in Subjects With COPD}

Table 2. Characteristics of Studies Included in This Review

\begin{tabular}{|c|c|c|c|c|c|}
\hline Reference & $\begin{array}{c}\text { Subjects } \\
\text { (Intervention/ } \\
\text { Control), } n\end{array}$ & $\begin{array}{c}\text { Subject } \\
\text { Characteristics }\end{array}$ & $\begin{array}{c}\text { Age } \\
\text { (Intervention/ } \\
\text { Control), } \\
\text { Mean } \pm \mathrm{SD}\end{array}$ & $\begin{array}{c}\text { Male } \\
\text { (Intervention/ } \\
\text { Control), } n\end{array}$ & Features \\
\hline Mota et $\mathrm{al}^{8}$ & $10 / 6$ & $\begin{array}{l}\text { Stage III or IV according to GOLD } \\
\text { classification; } \mathrm{FEV}_{1}: \% \text { of } \\
\text { predicted for intervention } \\
(27 \pm 3) \text { and sham }(28 \pm 3) \\
\text { groups (mean } \pm \mathrm{SD})\end{array}$ & $62 \pm 2 / 66 \pm 3$ & $10 / 6$ & $\begin{array}{l}\text { EMT group }=\text { general physiotherapy } \\
\text { techniques plus EMT with threshold; } \\
\text { load of } 50 \% \text { of } \mathrm{P}_{\mathrm{E}_{\max }} \text {; three } 30 \text {-min } \\
\text { sessions per week for } 5 \text { weeks } \\
\text { Control group = general physiotherapy } \\
\text { techniques plus threshold with no } \\
\text { additional load }\end{array}$ \\
\hline Nield et al ${ }^{20}$ & $7 / 9$ & $\begin{array}{l}\text { Stage III or IV according to GOLD } \\
\text { classification; } \mathrm{FEV}_{1}: \% \text { of } \\
\text { predicted for intervention } \\
(43 \pm 16) \text { and sham }(40 \pm 15) \\
\text { groups (mean } \pm \mathrm{SD})\end{array}$ & $63 \pm 5 / 69 \pm 8$ & $7 / 9$ & $\begin{array}{l}\text { EMT group }=\text { threshold with } 10 \% \text { of } \\
\text { the subject's baseline } \mathrm{P}_{\mathrm{E}_{\max }} \text { with the } \\
\text { objective of prolongation of } \\
\text { expiration; } 10 \text { min in the } 1 \text { st week, } \\
15 \text { min in the } 2 \text { nd week, } 20 \text { min in } \\
\text { the } 3 \text { rd week, and } 25 \text { min from the } \\
\text { 4th week for } 12 \text { weeks, every day } \\
\text { Control group = received pamphlets of } \\
\text { the American Lung Association }\end{array}$ \\
\hline Weiner et $\mathrm{al}^{4}$ & $12 / 11$ & $\begin{array}{l}\mathrm{FEV}_{1}<50 \% \text { of predicted and } \\
\mathrm{FEV}_{1} / \mathrm{FVC}<70 \% \text { of predicted } \\
\text { who received a diagnosis of } \\
\text { COPD according to the } \\
\text { American Thoracic Society } \\
\text { (Stage III or IV according to } \\
\text { GOLD classification); } \mathrm{FEV}_{1}: \\
\% \text { of predicted for intervention } \\
(37 \pm 2.4) \text { and sham }(39 \pm 2.9) \\
\text { groups (mean } \pm \mathrm{SD})\end{array}$ & $\begin{array}{c}63.3 \pm 2.9 / \\
61.1 \pm 2.8\end{array}$ & $9 / 10$ & $\begin{array}{l}\text { EMT group }=\text { threshold with } 15 \% \text { of } \\
\mathrm{P}_{\mathrm{E}_{\max }} \text { in the } 1 \text { st week, increasing the } \\
\text { load by } 5-10 \% \text { in each session up to } \\
60 \% \text {; weekly measurement of } \mathrm{P}_{\mathrm{E}_{\max }} \\
\text { with EMT maintained at } 60 \% \text { of the } \\
\text { value; } 30 \text { min } 6 \text { times per week for } \\
12 \text { weeks } \\
\text { Control group = threshold with } \\
7 \mathrm{~cm} \mathrm{H}_{2} \mathrm{O} \text {; same period and number } \\
\text { of sessions }\end{array}$ \\
\hline Weiner et $\mathrm{al}^{13}$ & 8 or $8 / 8$ & $\begin{array}{l}\mathrm{FEV}_{1}<50 \% \text { of predicted and } \\
\mathrm{FEV}_{1} / \mathrm{FVC}<0.7 \text { of predicted } \\
\text { who received a diagnosis of } \\
\text { COPD according the American } \\
\text { Thoracic Society (Stage III or } \\
\text { IV according to GOLD } \\
\text { classification); FEV }: \% \text { of } \\
\text { predicted for EMT }(43 \pm 2.6), \\
\text { EMT }+ \text { IMT }(45 \pm 3.0), \text { and } \\
\text { sham }(43 \pm 2.9) \text { groups } \\
\text { (mean } \pm \mathrm{SD})\end{array}$ & $\begin{array}{c}65.4 \pm 3.3 / \\
62.7 \pm 3 / \\
61.8 \pm 3.2\end{array}$ & 7 or $6 / 7$ & $\begin{array}{l}\text { EMT group = threshold with } 15 \% \text { of } \\
\mathrm{P}_{\mathrm{E}_{\max }} \text { in the } 1 \text { st week, increasing the } \\
\text { load by } 5-10 \% \text { in each session up to } \\
60 \% \text {; weekly measurement of } \mathrm{P}_{\mathrm{E}_{\max }} \text {, } \\
\text { with EMT maintained at } 60 \% \text { of the } \\
\text { value; } 30 \text { min } 6 \text { times per week for } \\
12 \text { weeks } \\
\text { EMT + IMT group = threshold with } \\
15 \% \text { of } \mathrm{P}_{\mathrm{E}_{\max }} \text { and } \mathrm{P}_{\mathrm{I}_{\max }} \text { in the } \\
1 \text { st week, increasing the load by } \\
5-10 \% \text { in each session up to } 60 \% \text {; } \\
\text { weekly measurement of } \mathrm{P}_{\mathrm{E}_{\max }} \text { and } \\
\mathrm{P}_{\mathrm{I}_{\max }} \text { with EMT }+ \text { IMT maintained } \\
\text { at } 60 \% \text { of the value; } 30 \text { min } 6 \text { times } \\
\text { per week for } 12 \text { weeks } \\
\text { Control group = threshold with } \\
7 \mathrm{~cm} \mathrm{H}_{2} \mathrm{O} \text {; same period and number } \\
\text { of sessions }\end{array}$ \\
\hline Battaglia et al ${ }^{21}$ & $16 / 16$ & $\begin{array}{l}\text { Stage III or IV according to GOLD } \\
\text { classification; } \mathrm{FEV}_{1}: \% \text { of } \\
\text { predicted for intervention } \\
(59.9 \pm 3.72) \text { and sham } \\
(55.65 \pm 4.12) \text { groups } \\
\text { (mean } \pm \mathrm{SD})\end{array}$ & $66 / 69$ & $10 / 9$ & $\begin{array}{l}\text { EMT + IMT group = Respivol alone } \\
\text { for } 10 \text { days, then Respivol plus } \\
\text { Respilift (using the mouth in } \\
\text { inspirations and expiration); } 30 \text { min } \\
\text { every day for } 40 \text { weeks } \\
\text { Control group = training at a load } \\
\text { known not to yield improvements in } \\
\text { inspiratory muscle training ( } \pm 5 \% \\
\left.\mathrm{P}_{\mathrm{I}_{\max }}\right)\end{array}$ \\
\hline \multicolumn{6}{|c|}{$\begin{array}{l}\text { EMT }=\text { expiratory muscle training } \\
\mathrm{P}_{\mathrm{E}_{\max }}=\text { maximum expiratory pressure } \\
\mathrm{IMT}=\text { inspiratory muscle training } \\
\mathrm{P}_{\mathrm{I}_{\max }}=\text { maximum inspiratory pressure }\end{array}$} \\
\hline
\end{tabular}


Table 3. Risk of Bias of Included Studies

\begin{tabular}{|c|c|c|c|c|c|}
\hline Reference & $\begin{array}{l}\text { Adequate Sequence } \\
\text { Generation }\end{array}$ & $\begin{array}{l}\text { Allocation } \\
\text { Concealment }\end{array}$ & $\begin{array}{c}\text { Blinding of } \\
\text { Outcome Assessors }\end{array}$ & $\begin{array}{c}\text { Description of } \\
\text { Losses and Exclusions }\end{array}$ & $\begin{array}{c}\text { Intention-to-Treat } \\
\text { Analysis }\end{array}$ \\
\hline Mota et $\mathrm{al}^{8}$ & Yes & Unclear & Yes & Yes & No \\
\hline Nield et al ${ }^{20}$ & Yes & Unclear & Unclear & Yes & No \\
\hline Battaglia et $\mathrm{al}^{21}$ & Yes & Yes & Unclear & Yes & Yes \\
\hline Weiner et $\mathrm{al}^{4}$ & Yes & Unclear & Yes & Yes & Yes \\
\hline Weiner et $\mathrm{al}^{13}$ & Yes & Unclear & Yes & No & Yes \\
\hline
\end{tabular}

\begin{tabular}{|c|c|c|c|c|c|c|c|c|c|}
\hline \multirow[b]{2}{*}{ Study or Subgroup } & \multicolumn{3}{|c|}{ EMT } & \multicolumn{3}{|c|}{ Control } & \multicolumn{2}{|r|}{ Mean Difference } & \multirow{2}{*}{$\begin{array}{c}\text { Mean Difference } \\
\text { IV, Random, 95\% C }\end{array}$} \\
\hline & Mean & $\mathrm{SD}$ & Total & Mean & $\mathrm{SD}$ & Total & Weight & IV, Random, 95\% Cl & \\
\hline \multicolumn{10}{|l|}{$\mathrm{P}_{\mathrm{E}_{\max }}$} \\
\hline Mota et al, 2007 & 147 & 37.9 & 10 & 131 & 19.5 & 6 & $8.3 \%$ & $16.00[-12.20,44.20]$ & \\
\hline Nield et al, 2007 & 104 & 31 & 7 & 96 & 35 & 9 & $6.3 \%$ & $8.00[-24.41,40.41]$ & \\
\hline Weiner et al, 2003a & 104 & 16.9 & 12 & 80 & 13.2 & 11 & $43.1 \%$ & $24.00[11.66,36.34]$ & \\
\hline Weiner et al, 2003b & 100 & 13.8 & 8 & 78 & 11.5 & 8 & $42.4 \%$ & $22.00[9.55,34.45]$ & \\
\hline Subtotal $(95 \% \mathrm{Cl})$ & & & 37 & & & 34 & $100.0 \%$ & $21.49[13.39,29.59]$ & \\
\hline \multicolumn{10}{|c|}{$\begin{array}{l}\text { Heterogeneity: } \text { Tau }^{2}=0.00 ; \text { Chi }^{2}=0.98, d f=3(P=.81) ;\left.\right|^{2}=0 \% \\
\text { Test for overall effect: } Z=5.20(P<.00001)\end{array}$} \\
\hline \multicolumn{10}{|l|}{$\mathrm{P}_{\mathrm{I}_{\text {max }}}$} \\
\hline Nield et al, 2007 & 77 & 25 & 7 & 67 & 18 & 9 & $9.5 \%$ & $10.00[-11.94,31.94]$ & \\
\hline Weiner et al, 2003a & 63 & 12.1 & 12 & 57 & 9.6 & 11 & $58.1 \%$ & $6.00[-2.89,14.89]$ & \\
\hline Weiner et al, 2003b & 69 & 13.2 & 8 & 59 & 11 & 8 & $32.4 \%$ & $10.00[-1.91,21.91]$ & \\
\hline Subtotal $(95 \% \mathrm{Cl})$ & & & 27 & & & 28 & $100.0 \%$ & $7.68[0.90,14.45]$ & \\
\hline \multicolumn{10}{|c|}{$\begin{array}{l}\text { Heterogeneity: } \text { Tau }^{2}=0.00 ; \text { Chi }^{2}=0.98, d f=3(P=.81) ;\left.\right|^{2}=0 \% \\
\text { Test for overall effect: } Z=5.20(P<.00001)\end{array}$} \\
\hline
\end{tabular}

Fig. 2. Comparison between expiratory muscle training (EMT) and control groups for maximum expiratory pressure $\left(P_{E_{\max }}\right)$ and maximum inspiratory pressure $\left(\mathrm{P}_{\mathrm{I}_{\max }}\right)$.

\begin{tabular}{|c|c|c|c|c|c|c|c|c|c|}
\hline \multirow[b]{2}{*}{ Study or Subgroup } & \multicolumn{3}{|c|}{ EMT } & \multicolumn{3}{|c|}{ Control } & \multicolumn{2}{|r|}{ Mean Difference } & \multirow{2}{*}{$\begin{array}{c}\text { Mean Difference } \\
\text { IV, Random, } 95 \% \mathrm{CI}\end{array}$} \\
\hline & Mean & SD & Total & Mean & SD & Total & Weight & IV, Random, $95 \% \mathrm{Cl}$ & \\
\hline Mota et al, 2007 & 474 & 111.1 & 10 & 423 & 109.8 & 6 & $37.8 \%$ & $51.00[-60.63,132.63]$ & \\
\hline Weiner et al, 2003a & 312 & 162 & 12 & 300 & 145.64 & 11 & $29.8 \%$ & $12.00[-113.73,137.73]$ & \\
\hline Weiner et al, 2003b & 304 & 132.5 & 8 & 285 & 112.8 & 8 & $32.4 \%$ & $19.00[-101.58,139.58]$ & \\
\hline Total $(95 \% \mathrm{Cl})$ & & & 30 & & & 25 & $100.0 \%$ & $29.01[-39.62,97.65]$ & \\
\hline \multicolumn{9}{|c|}{ Heterogeneity: Tau $^{2}=0.00 ; \mathrm{Chi}^{2}=0.25, \mathrm{df}=2(\mathrm{P}=.88) ; \mathrm{I}^{2}=0 \%$} & 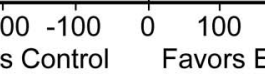 \\
\hline
\end{tabular}

Fig. 3. Comparison between expiratory muscle training (EMT) and control groups for the 6-min walk test.

interventions, including pulmonary rehabilitation. ${ }^{32}$ It is possible that non-favorable results were found for dyspnea and 6MWT because of the small number of studies included and the small number of individuals in each study.

Of the 2 studies that evaluated dyspnea, one seems to be favorable to $\mathrm{EMT}^{8}$ and the other one not. ${ }^{20}$ One of the causes of these findings is that the study conducted by Nield et $\mathrm{al}^{20}$ used a training protocol to prolong expiration and not to strengthen expiratory muscles. The authors used only $10 \%$ of the subject's baseline $\mathrm{P}_{\mathrm{E}_{\max }}$ in the training protocol. Another important consideration regarding this study is that the subjects evaluated had less severe COPD compared with the others.

When we analyzed EMT combined with IMT versus the control group, we found higher $\mathrm{P}_{\mathrm{E}_{\max }}$ and $\mathrm{P}_{\mathrm{I}_{\max }}$. These results of EMT combined with IMT for these variables may be due to the combination of 2 effective forms of respiratory muscle training. A recent systematic review showed that in normal subjects, the combination of IMT plus EMT is more effective in increasing the performance exercise compared with IMT or the control group. ${ }^{33}$ 


\begin{tabular}{|c|c|c|c|c|c|c|c|c|c|}
\hline \multirow[b]{2}{*}{ Study or Subgroup } & \multicolumn{3}{|c|}{ EMT } & \multicolumn{3}{|c|}{ Control } & \multicolumn{2}{|r|}{ Mean Difference } & \multirow{2}{*}{$\begin{array}{c}\text { Mean Difference } \\
\text { IV, Random, } 95 \% \mathrm{Cl}\end{array}$} \\
\hline & Mean & SD & Total & Mean & SD & Total & Weight & IV, Random, 95\% Cl & \\
\hline Mota et al, 2007 & 4 & 0.1 & 10 & 3 & 2.4 & 6 & $23.0 \%$ & $1.00[-0.92,2.92]$ & 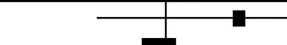 \\
\hline Nield et al, 2007 & 3.9 & 0.7 & 7 & 4 & 1.4 & 9 & $77.0 \%$ & $-0.10[-1.15,0.95]$ & \\
\hline Total $(95 \% \mathrm{Cl})$ & & & 17 & & & 15 & $100.0 \%$ & $0.15[-0.7,1.08]$ & \\
\hline \multicolumn{9}{|c|}{$\begin{array}{l}\text { Heterogeneity: } \mathrm{Tau}^{2}=0.00 ; \mathrm{Chi}^{2}=0.97, \mathrm{df}=1(\mathrm{P}=.32) ; \mathrm{I}^{2}=0 \% \\
\text { Test for overall effect: } \mathrm{Z}=0.33(\mathrm{P}=.74)\end{array}$} & 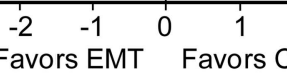 \\
\hline
\end{tabular}

Fig. 4. Comparison between expiratory muscle training (EMT) and control groups for dyspnea.

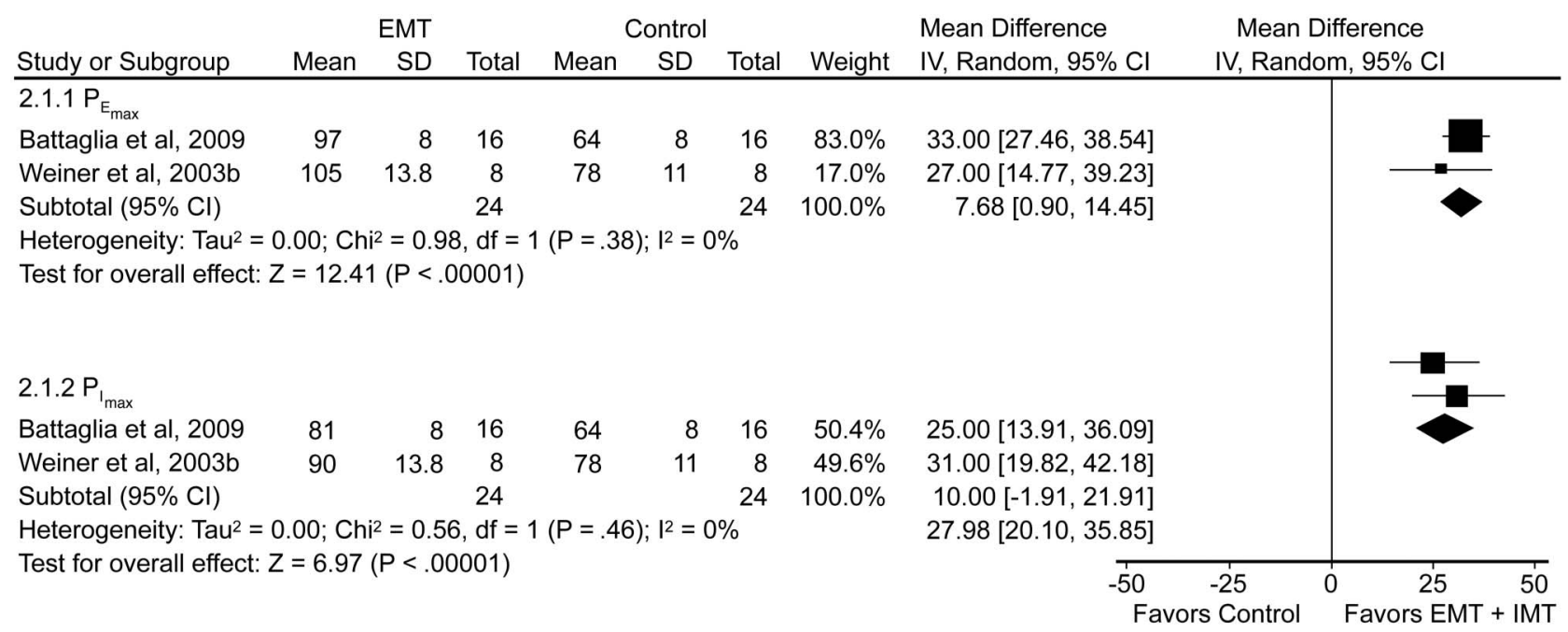

Fig. 5. Comparison between expiratory muscle training (EMT) combined with inspiratory muscle training (IMT) and control groups for maximum expiratory pressure $\left(\mathrm{P}_{\mathrm{E}_{\max }}\right)$ and maximum inspiratory pressure $\left(\mathrm{P}_{\mathrm{I}_{\max }}\right)$.

IMT is already well elucidated in the literature as a good method to increase inspiratory muscle strength. ${ }^{10-12}$ In this meta-analysis, we found that EMT is an effective way to improve strength of the inspiratory and expiratory muscles. Hence, as expected, the combination of EMT and IMT showed very good results for improving respiratory muscle strength. However, it was not possible to determine which is the best technique to increase expiratory muscle strength, EMT or EMT plus IMT, through this meta-analysis.

\section{Strengths and Limitations of the Review}

An important positive factor is that there was no heterogeneity of the studies included in these meta-analyses. Another strong methodological point was the systematic review of the literature, with explicit and reproducible eligibility criteria, without language limitations, performed independently by 2 reviewers.

A limitation of the studies included in this review is that most of them presented low methodological quality. None of the studies had a description of the sample calculation. Only the study carried out by Battaglia et $\mathrm{al}^{21}$ described randomization to be based on a sealed envelope random- ization list. All of the studies described the exclusions, ${ }^{4,8,13,20,21}$ and only one study ${ }^{13}$ did not describe losses. Three studies $4,8,13$ described the blinding of outcome assessors. Some types of intervention allow blinding of subjects enrolled in the study. This was shown in the studies in which the sham group performed the same intervention as the intervention group but with a different load in "Threshold," for example. In this paper, this method can be seen in 2 studies. ${ }^{4,13}$ Moreover, there were a limited number of studies included in this review since only 5 of them met the eligibility criteria, showing a lack of studies on the interventions in this population. Perhaps with a higher number of studies and individuals included in the analyses, it would be possible to show the benefit of EMT on the distance walked in 6MWT and dyspnea. Another limitation of this review concerns the EMT protocols and the loads used in the studies. Nield et $\mathrm{al}^{20}$ used a program of prolonged exhalation with EMT and not expiratory muscle strengthening. This protocol was different from that used in the other studies included in this paper. In the studies that used a device to increase expiratory muscle strength, there were differences in the training load used ranging from 10 to $60 \%$ of $\mathrm{P}_{\mathrm{E}_{\max }}$. 


\section{Respiratory Muscle Training in Subjects With COPD}

\section{Conclusions}

This systematic review and meta-analysis showed that EMT and EMT combined with IMT increase respiratory muscle strength but not functional capacity and dyspnea. Thus, this intervention can be used as part of the treatment during pulmonary rehabilitation of subjects with severe to very severe COPD. However, further studies with a more robust methodological design and a greater number of individuals are necessary to adequately respond to these issues.

\section{REFERENCES}

1. Sin DD, Anthonisen NR, Soriano JB, Agusti AG. Mortality in COPD: role of comorbidities. Eur Respir J 2006;28(6):1245-1257.

2. Perera PN, Armstrong EP, Sherrill DL, Skrepnek GH. Acute exacerbations of COPD in the United States: inpatient burden and predictors of costs and mortality. COPD 2012;9(2):131-141.

3. Antunes FP, Costa Mda C, Paim JS, Vieira-da-Silva LM, Santos CA, Cruz AA, Barreto ML. Trends in hospitalizations for respiratory diseases in Salvador, Bahia State, Brazil, 1998-2009. Cad Saude Publica 2012;28(5):869-877.

4. Weiner P, Magadle R, Beckerman M, Weiner M, Berar-Yanay N. Specific expiratory muscle training in COPD. Chest 2003;124(2): 468-473.

5. Agustí AG. Systemic effects of chronic obstructive pulmonary disease. Proc Am Thorac Soc 2005;2(4):367-370; discussion 371-362.

6. Scherer TA, Spengler CM, Owassapian D, Imhof E, Boutellier U. Respiratory muscle endurance training in chronic obstructive pulmonary disease: impact on exercise capacity, dyspnea, and quality of life. Am J Respir Crit Care Med 2000;162(5):1709-1714.

7. Salman GF, Mosier MC, Beasley BW, Calkins DR. Rehabilitation for patients with chronic obstructive pulmonary disease: meta-analysis of randomized controlled trials. J Gen Intern Med 2003;18(3): 213-221.

8. Mota S, Güell R, Barreiro E, Solanes I, Ramírez-Sarmiento A, OrozcoLevi M, et al. Clinical outcomes of expiratory muscle training in severe COPD patients. Respir Med 2007;101(3):516-524.

9. Weiner P, McConnell A. Respiratory muscle training in chronic obstructive pulmonary disease: inspiratory, expiratory, or both? Curr Opin Pulm Med 2005;11(2):140-144.

10. Lötters F, van Tol B, Kwakkel G, Gosselink R. Effects of controlled inspiratory muscle training in patients with COPD: a meta-analysis. Eur Respir J 2002;20(3):570-576.

11. Weiner P, Azgad Y, Ganam R. Inspiratory muscle training combined with general exercise reconditioning in patients with COPD. Chest 1992;102(5):1351-1356.

12. Ramirez-Sarmiento A, Orozco-Levi M, Guell R, Barreiro E, Hernandez $\mathrm{N}$, Mota $\mathrm{S}$, et al. Inspiratory muscle training in patients with chronic obstructive pulmonary disease: structural adaptation and physiologic outcomes. Am J Respir Crit Care Med 2002;166(11):14911497.

13. Weiner P, Magadle R, Beckerman M, Weiner M, Berar-Yanay N. Comparison of specific expiratory, inspiratory, and combined muscle training programs in COPD. Chest 2003;124(4):1357-1364.

14. Langer D, Hendriks E, Burtin C, Probst V, van der Schans C, Paterson W, et al. A clinical practice guideline for physiotherapists treating patients with chronic obstructive pulmonary disease based on a systematic review of available evidence. Clin Rehab 2009; 23(5):445-462.
15. Crisafulli E, Costi S, Fabbri LM, Clini EM. Respiratory muscles training in COPD patients. Int J Chron Obstruct Pulmon Dis 2007; 2(1): $19-25$

16. Higgins J, Green S. Cochrane handbook for systematic reviews of interventions. England: Wiley; 2008.

17. Moher D, Liberati A, Tetzlaff J, Altman DG. Preferred reporting items for systematic reviews and meta-analyses: the PRISMA Statement. Open Med 2009;3(3):e123-e130.

18. Robinson KA, Dickersin K. Development of a highly sensitive search strategy for the retrieval of reports of controlled trials using PubMed. Int J Epidemiol 2002;31(1):150-153.

19. Higgins JP, Thompson SG, Deeks JJ, Altman DG. Measuring inconsistency in meta-analyses. BMJ 2003;327(7414):557-560.

20. Nield MA, Soo Hoo GW, Roper JM, Santiago S. Efficacy of pursedlips breathing: a breathing pattern retraining strategy for dyspnea reduction. J Cardiopulm Rehabil Prev 2007;27(4):237-244.

21. Battaglia E, Fulgenzi A, Ferrero ME. Rationale of the combined use of inspiratory and expiratory devices in improving maximal inspiratory pressure and maximal expiratory pressure of patients with chronic obstructive pulmonary disease. Arch Phys Med Rehabil 2009;90(6): 913-918.

22. Hodgev VA, Kostianev SS. Maximal inspiratory pressure predicts mortality in patients with chronic obstructive pulmonary disease in a five-year follow-up. Folia Med 2006;48(3-4):36-41.

23. Vilaró J, Ramirez-Sarmiento A, Martínez-Llorens JM, Mendoza T, Alvarez M, Sánchez-Cayado N, et al. Global muscle dysfunction as a risk factor of readmission to hospital due to COPD exacerbations. Respir Med 2010;104(12):1896-1902.

24. Mesquita R, Donária L, Genz IC, Pitta F, Probst VS. Respiratory muscle strength during and after hospitalization for COPD exacerbation. Respir Care 2013;58(12):2142-2149.

25. Soler-Cataluña JJ, Martínez-García MA, Román Sánchez P, Salcedo E, Navarro M, Ochando R. Severe acute exacerbations and mortality in patients with chronic obstructive pulmonary disease. Thorax 2005; 60(11):925-931.

26. Ninane V, Rypens F, Yernault JC, De Troyer A. Abdominal muscle use during breathing in patients with chronic airflow obstruction. Am Rev Respir Dis 1992;146(1):16-21.

27. Castro AA, Kümpel C, Rangueri RC, Oliveira MD, Dornelles RA, Brito ER, et al. Daily activities are sufficient to induce dynamic pulmonary hyperinflation and dyspnea in chronic obstructive pulmonary disease patients. Clinics 2012;67(4):319-325.

28. O'Donnell DE, D'Arsigny C, Fitzpatrick M, Webb KA. Exercise hypercapnia in advanced chronic obstructive pulmonary disease: the role of lung hyperinflation. Am J Respir Crit Care Med 2002;166(5): 663-668.

29. O’Donnell DE, Revill SM, Webb KA. Dynamic hyperinflation and exercise intolerance in chronic obstructive pulmonary disease. Am J Respir Crit Care Med 2001;164(5):770-777.

30. Kessler R, Faller M, Fourgaut G, Mennecier B, Weitzenblum E. Predictive factors of hospitalization for acute exacerbation in a series of 64 patients with chronic obstructive pulmonary disease. Am J Respir Crit Care Med 1999;159(1):158-164.

31. Pinto-Plata VM, Cote C, Cabral H, Taylor J, Celli BR. The 6-min walk distance: change over time and value as a predictor of survival in severe COPD. Eur Respir J 2004;23(1):28-33.

32. Nici L, Donner C, Wouters E, Zuwallack R, Ambrosino N, Bourbeau $\mathrm{J}$, et al. American Thoracic Society/European Respiratory Society statement on pulmonary rehabilitation. Am J Respir Crit Care Med 2006;173(12):1390-1413.

33. Illi SK, Held U, Frank I, Spengler CM. Effect of respiratory muscle training on exercise performance in healthy individuals: a systematic review and meta-analysis. Sports Med 2012;42(8):707-724. 